Send your letters to the Editor,

British Dental Journal,

64 Wimpole Street

London

W1G 8YS

Email bdj@bda.org

Priority will be given to letters less than 500 words long.

Authors must sign the letter, which

may be edited for reasons of space.

\section{CHANGE THE BATHWATER}

Sir, a recent cohort study of caries incidence in 739 children in the journal highlighted the importance of prevention in primary teeth. ${ }^{1}$ The authors observe that caries diagnosis in this study did not include radiographic examination, so it is likely, therefore, that many of these apparently caries-free children had undiagnosed approximal lesions at presentation. ${ }^{2}$ For this reason we agree wholeheartedly with the conclusion that, whether caries is obvious or not, all children require preventive care, for which evidence-based guidelines are readily available. ${ }^{3,4}$

However, none of these guidelines recommend a prevention-only approach to caries management once cavitation has been diagnosed. Based on their own retrospective data, the same group have suggested that the sequelae of dental caries (pain, sepsis, extractions) cannot be controlled by restorative intervention either. ${ }^{5}$

The question of whether primary tooth restorations are effective or not in managing caries would seem more complex than either side in this increasingly polarised argument are prepared to admit. Two recent systematic reviews show that amalgam, ${ }^{6}$ compomers, or resin modified glass ionomers ${ }^{7}$ can be used with success in primary teeth. Further inspection of the individual studies reported in these reviews suggests that pain and infection are uncommon sequelae. For example, Qvist $^{8}$ followed over 1,500 Class II restorations in 971 children for seven years. Treatment was undertaken by non-specialists in the Danish Public Dental Health Services, and only 7\% of teeth subsequently presented with sepsis or were extracted. However, a recent UK randomised controlled trial investigated clinical outcomes of the Hall Technique with those of standard restorations provided by GDPs for carious primary molars. ${ }^{9}$ For the 129 children followed up for two years, only $2 \%(n=3)$ of the Hall crown teeth had abscessed or become unrestorable, while for the teeth with standard restorations this was 15\% ( $\mathrm{n}=$ 19), a figure approaching that reported by the Manchester group for teeth left unrestored! How could the UK results be so different from those reported by Qvist? There are a number of possible reasons, but further examination of the data shows that the material of choice for the majority of GDPs when restoring Class IIs was unmodified glass ionomer cement, a material now regarded as unsatisfactory for this purpose. ${ }^{7}$ GDPs clearly want to provide the best possible care for their child patients, so what are the barriers to the use of techniques and materials (amalgam, compomers, composites or resin modified glass ionomers) of proven effectiveness in general practice? These obstacles, be they funding, education, access to specialist care or something else altogether, need to be further explored and then addressed.

Repeated demonstration that what is currently being provided is inadequate for children in the UK does not mean that the baby (reduction in pain and sepsis for UK children) should be thrown out with the bathwater (current restorative methods in the general practice environment). Perhaps the bathwater simply needs changing!

B. Chadwick, R. Borland, D. Evans, N. Innes, J. Mackie, E. Treasure, G. Topping, J. Steele

By email

1. Milsom K M, Blinkhorn A S, Tickle M. The incidence of dental caries in the primary molar teeth of young children receiving National Health Service funded dental care in practices in the North West of England. Br Dental J 2008; 205: E14
2. Kidd E A M, Pitts N B. A reappraisal of the value of the bitewing radiograph in the diagnosis of posterior approximal caries. Br Dent J 1990: 169: 195-200.

3. Department of Health and the British Association for the Study of Community Dentistry. Delivering better oral health: an evidence-based toolkit for prevention. 2007. http://www.dh.gov.uk/en/Publicationsandstatistics/Publications/PublicationsPolicyAndGuidance/DH_078742

4. Scottish Intercollegiate Guideline Network. Prevention and management of dental decay in the pre-school child. SIGN Publication No. 83. http://www.sign.ac.uk/pdf/sign83.pdf

5. Tickle M, Milsom K M, Kearney-Mitchell $P_{\text {, }}$ Blinkhorn A S. The fate of carious primary teeth of children who regularly attend the general dental service. Br Dent J 2002; 192: 219-223.

6. Kilpatrick N P, Newmann A. Durability of amalgams in restoration of class II cavities in primary molars: a systematic review of the literature. Eur Arch Paediatr Dent 2007; 8: 5-13.

7. Chadwick B L, Evans D J P. Restorations of class II cavities in primary molar teeth with conventional and resin modified glass ionomer cements: a systematic review of the literature. Eur Arch Paediatr Dent 2007; 8: 14-21.

8. Qvist V, Laurberg L, Poulsen A, Teglers P T. Class II restorations in primary teeth: 7-year study on three resin-modified glass ionomer cements and a compomer. Eur J Oral Sci 2004; 112: 188-196.

9. Innes N P T, Evans D J P, Stirrups D R. The Hall Technique: a randomized controlled clinical trial of a novel method of managing carious primary molars in general dental practice; acceptability of the technique and outcomes at 23 months. BMC Oral Health 2007; 7: 18.

DOI: $10.1038 /$ sj.bdj.2008.895

\section{DERMATITIS RISK}

Sir, we wish to draw attention to our concerns about the risks of work-related dermatitis to dental workers, particularly from frequent hand washing and use of disposable gloves.

Reports from dermatologists show that dentists and dental care professionals have a 6- to 11-fold higher than average risk of developing work-related contact dermatitis ${ }^{1}$ cited agents are personal protective equipment including gloves, rubber chemicals (believed to be related to glove use), wet-work, resins and acrylics.

Knowledge of dermatitis risks and control measures was assessed by a questionnaire completed by 132 respondents, mainly dentists, attending the 
successful Annual Dental Symposium of the Northern Deanery entitled 'The Future in your Hands'. Many were aware of work-related dermatitis; it was unfortunate that for some, this was through personal experience of work-related dermatitis (about 10\%).

As to the causes, there was good awareness of the risks from natural rubber latex (NRL); those delegates who were more recently qualified were aware of latex issues from their undergraduate training. There was poorer awareness of the risk of dermatitis from wet-work (which includes hand washing) and rubber chemicals which may be released from NRL and non-NRL gloves, powdered or not. Some were of the misconception that if they are not currently allergic to single-use gloves then they will not develop a glove allergy in the future. About 10\% of respondents used 'powdered' NRL gloves, which is a practice that is difficult to reconcile with the relevant advice..$^{3-5}$

Given the knowledge of the risks, most had policies in place. Some had gone further than others to manage the risks. About $40 \%$ of respondents had access to workplace emollient creams whilst a relatively small number used 'skin checks' (21\%).

Frequent hand cleaning, wet-work and the wearing of single-use gloves is a feature of dental work, and therefore the focus of control measures must be good skin care, such as emollient use and checking for early signs of dermatitis. For example, staff should be aware of the risks of contact dermatitis from:

- Rubber chemicals (eg thiurams) which can be present in both non-NRL and NRL disposable gloves; (proteins also present in NRL gloves can cause allergic reactions in sensitive individuals)

- Wet-work; as a guide - more than two hours a day or about 20 to 40 hand washes a day.

Staff should be aware of how to:

- Maintain good skin condition Employers should consider:

- Supplying workplace emollients

- Use skin checking by a 'responsible' person. ${ }^{2}$

More information is available through HSE's 'Skin at Work' webpages, as well as the British Dental Association and the Faculty of General Dental Practice amongst others.

\section{G. Cartlidge, Liverpool \\ D. Sen, Manchester}

1. Data from the Health and Occupation Reporting network (THOR), provided by Centre for Occupational and Environmental Health, University of Manchester. http://www.hse.gov.uk/statistics/ causdis/dermatitis/scale.htm

2. Health \& Safety Executive. Medical aspects of occupational skin disease. Guidance Note MS 24 (Second edition). http://www.hse.gov.uk/pubns/ms24.pdf

3. British Dental Association. Infection control in dentistry. Advice sheet A12. London: BDA, 2003.

4. Health \& Safety Executive. Latex and you. www. hse.gov.uk/pubns/INDG320.pdf

5. Health \& Safety Executive. Dermatitis Inspection Topic Pack. http://www.hse.gov.uk/skin/professional/inspectors.htm

\section{DOI: $10.1038 /$ sj.bdj.2008.896}

\section{WORK OVERLOOKED}

Sir, I write regarding the continuation of an inaccuracy cited in the article Unexplained orofacial pain - is an early diagnosis possible? (BDJ 2008; 205: E6). The article questions evidence of successful resolution of pain symptoms with occlusal adjustment. Cited are literature review papers. These reviews have overlooked published work by Kerstein et $a l .{ }^{1-7}$ The success of occlusal adjustment is dependent on timing of disclusion and occlusion, not ultimate force. It is the medium used by clinicians, namely articulating paper, that limits success. If a higher degree of precision is delivered, the evidence does suggest a significant success rate can be expected.

\section{Holland}

By email

1. Kerstein R B, Chapman R, Klein M. A comparison of ICAGD (Immediate Complete Anterior Guidance Development) to Mock ICAGD for symptom reductions in chronic myofascial pain dysfunction patient. J Craniomandibular Pract 1997; 5: 21-37.

2. Kerstein R B. A comparison of traditional occlusal equilibration and immediate complete anterior guidance development. J Craniomandibular Pract 1993: 11: 126-140.

3. Kerstein R B. Disclusion time measurement studies: a comparison of disclusion time between chronic myofascial pain dysfunction patients and nonpatients: a population analysis. J Prosthet Dent 1994; 72: 473-480

4. Kerstein R B, Wright N R. Electromyographic and computer analyses of patients suffering from chronic myofascial pain-dysfunction syndrome: before and after treatment with immediate complete anterior guidance development. J Prosthet Dent 1991; 66: 677-686.

5. Kerstein R B. Disocclusion time-reduction therapy with immediate complete anterior guidance development to treat chronic myofascial pain-dysfunction syndrome. Quintessence Int 1992; 23: 735-747.

6. Kerstein R B. Treatment of myofascial pain dysfunction syndrome with occlusal therapy to reduce lengthy disclusion time - a recall evaluation. J Craniomandibular Pract 1995; 13: 105-115.

7. Kerstein R B, Farrell S. Treatment of myofascial pain-dysfunction syndrome with occlusal equilibration. J Prosthet Dent 1990; 63: 695-700.

Dr Vishal Aggarwal responds: Many thanks for your feedback. My main comment to Mr Holland's letter is that to practise evidence-based dentistry we have to follow a hierarchy of evidence and the strongest evidence is from systematic reviews, particularly Cochrane systematic reviews which pool together the results of high quality randomised controlled trials. Such a review conducted by Koh and Robinson which we have quoted in our paper has shown occlusal adjustments cannot be used in the treatment and prevention of TMD as no evidence was found when all trials investigating this intervention were pooled together. I also believe the GDC looks seriously at cases of occlusal adjustment carried out to treat TMD and practitioners should approach with extreme caution when using such treatments. Rather, noninvasive treatments would be better as they have the potential to provide benefit without resulting in harm. Cognitive behaviour therapy has been shown to be effective as a non-invasive treatment. ${ }^{1-8}$

I would recommend that readers must critique evidence very thoroughly before accepting the results of any studies and the FDGP UK have developed critical appraisal guidelines for this very purpose.

Turner $J$ A, Holtzman S, Mancl L. Mediators, moderators, and predictors of therapeutic change in cognitive-behavioral therapy for chronic pain. Pain 2007: 127: 276-286.

2. Gatchel RJ, Stowell A W, Wildenstein L, Riggs R, Ellis $E$, III. Efficacy of an early intervention for patients with acute temporomandibular disorder-related pain: a one-year outcome study. J Am Dent Assoc 2006; 137: 339-347.

3. Dworkin SF, Turner JA, Wilson Let al. Briefgroup cognitive-behavioral intervention for temporomandibular disorders. Pain 1994:59: 175-187.

4. Turk DC, Rudy TE, Kubinski J A, Zaki HS, Greco CM. Dysfunctional patients with temporomandibular disorders: evaluating the efficacy of a tailored treatment protocol. J Consult Clin Psychol 1996; 64: 139-146.

5. Dworkin S F, Turner J A, Mancl L et al. A randomized clinical trial of a tailored comprehensive care treatment program for temporomandibular disorders. J Orofac Pain 2002; 16: 259-276.

6. Dworkin S F, Huggins K H, Wilson Let al. A randomized clinical trial using research diagnostic criteria for temporomandibular disorders-axis II to target clinic cases for a tailored self-care TMD treatment program. J Orofac Pain 2002; 16: 48-63.

7. Turner J A, Mancl L, Aaron L A. Brief cognitivebehavioral therapy for temporomandibular disorder pain: effects on daily electronic outcome and process measures. Pain 2005; 117: 377-387.

8. Turner J A, Mancl L, Aaron LA. Short-and long-term efficacy of brief cognitive-behavioral therapy for patients with chronic temporomandibular disorder pain: a randomized, controlled trial. Pain 2006; 121: 181-194.

DOI: 10.1038/sj.bdj.2008.897 


\section{TEA TOWEL SIGN}

Sir, we would like to draw your readers' attention to a sign that we observed when working in the Philippines, and also in our home units: the tea towel sign of maxillofacial deformity. The two scenarios in which we have seen this sign are described below.

Oral and nasal competence is maintained by an intact dynamic muscular and mucosal seal. A competent oral sphincter and nasal aperture is imperative to the function of the oral cavity and nasopharynx.

This can be compromised by congenital or acquired craniomaxillofacial deformity. This seal can be, in part, restored by the positioning of a tea towel over the face.

In the developing world where oral and maxillofacial surgery is not freely and readily available many patients will use a tea towel or a bandana to cover their deformity. The tea towel has numerous functions including absorbing saliva and nasal secretions, preventing the drying out of the oral and nasal cavity and it allows alterations in voice. Furthermore the tea towel hides the deformity from view of the patient in the mirror and from other people. Many people without deformity in the developing world use face masks and bandanas to cover the entrance to their aerodigestive tract to prevent fumes and carbioniferous toxins entering. With this as an excuse many can secretly hide their deformity (Figs 1-4).

In the developed world, a tea towel is normally held by a patient who has suffered severe trauma. Oral and maxillofacial and other facial reconstructive services are available to deal with most congenitial facial deformity. In this situation, as well as hiding the deformity, the tea towel soaks up blood, allows adequate pressure to prevent further bleeding and prevents drying of the oral and nasal mucosa.

The reasons for using a tea towel (or equivalent) to cover the face are multifactorial, nonetheless it can be a sign of untreated oral and maxillofacial deformity.

T. W. M. Walker, Galway

S. C. Mackay, P. Ayliffe, London

J. Curtin, Darwin

DOI: 10.1038/sj.bdj.2008.898

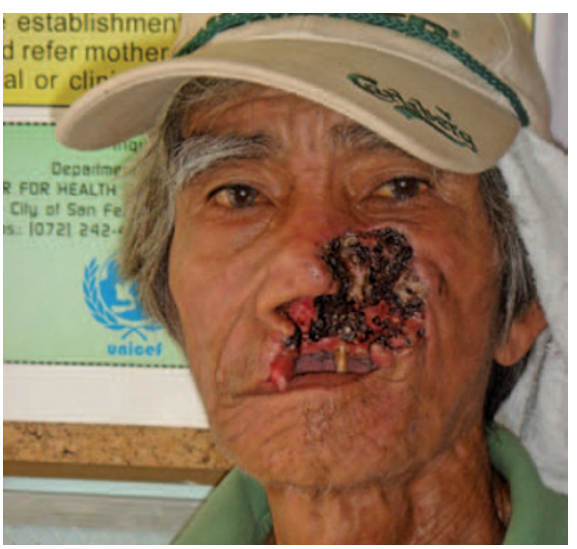

Fig. 1 77-year-old man with destructive lesion of the left nasolabial region

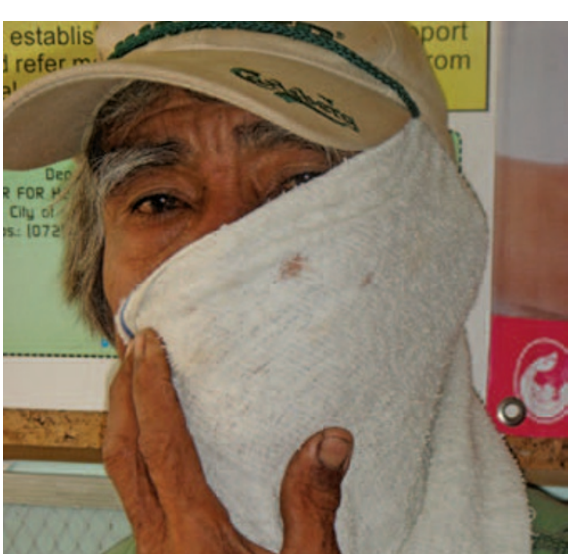

Fig. 2 Same man hiding deformity with a tea towel

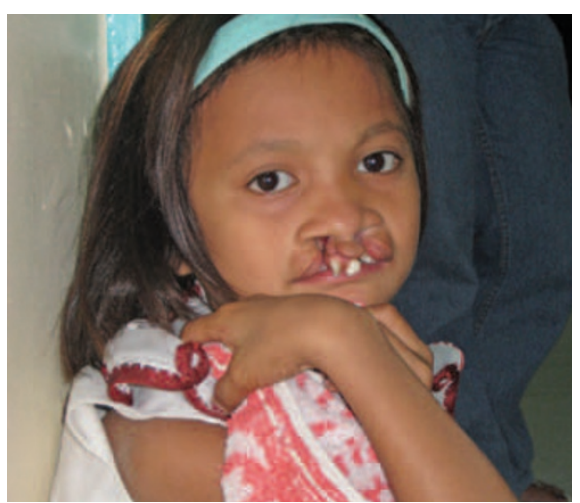

Fig. 3 7-year-old girl with a bilateral cleft lip and palate

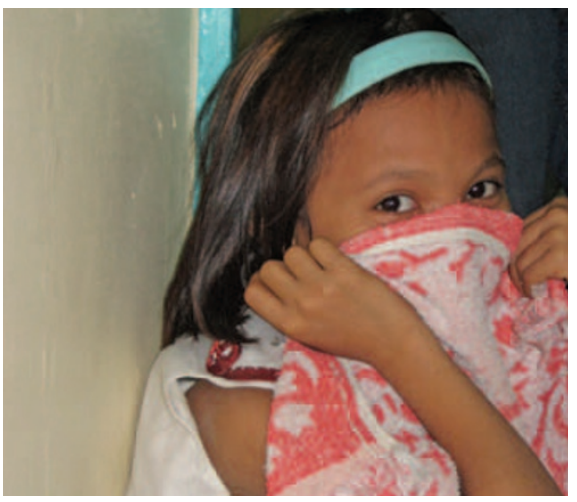

Fig. 4 Same girl hiding deformity with a tea towel 